UDC 622.6

S. I. Trubachev ${ }^{1}$, associate professor,

DOI: http://dx.doi.org/10.20535/2219-380413201568994

O. N. Alekseychuk ${ }^{2}$, associate professor

\title{
APPLYING THE VARIATIONAL-GRID METHOD OF THE SUPPORTED SHELLS CALCULATION
}

Ua У даній роботі розглядається методика розрахунку підкріплених пологих оболонок, яка заснована на використанні методів нелінійного програмування, а саме методу по координатного спуску, при розв'язанні завдання мінімізації повної потенційної енергії системи на скінченновимірному просторі допустимих переміщень. Для побудови скінченновимірної задачі використовувалися трикутні скінчені елементи для пологої оболонки. Була досліджена збіжність рішення.

Ru В данной работе рассматривается методика расчета подкрепленных пологих оболочек, которая основана на использовании методов нелинейного программирования, а именно метода покоординатного спуска, при решении задачи минимизации полной потенциальной энергии системы на конечномерном пространстве допустимых перемещений. Для построения конечномерной задачи использовались треугольные конечные элементы для пологой оболочки. Была исследована сходимость решения.

\section{Introduction}

The literature on the theory of shells shows a number of variants of the statics and dynamics equations for ribbed shells from. The classification of most of these variants is produced by the methods of A. I. Lur'e and V. E. Vlasov [1]. These approaches are based on combining equations that describe deformation of the shell (in accordance with Kirchhoff's hypothesis) and deformation of the rods (in accordance with the hypothesis of rigid sections). A theory of ribbed shells has a number of contradictions, presented by the fact that deformation of ribbed shells is described by the twelfth-order equations with a number of terms that have no meaning in the mechanical theory of shells. As an example, there are fourth-order derivative of tangential displacements; equations of the theory of ribbed shells are conjugated and have nonelliptic type.

\section{Statement of the problem and basic relations}

The method of reducing the ribbed shell is used, when we have a large number of frequently spaced ribs. It is clear that in this case the stress-strain state near the edges is distorted. There is a number of the unresolved questions:

\footnotetext{
${ }^{1}$ National Technical University of Ukraine "Kyiv Polytechnic Institute", Department of Dynamics and Strength of Machines and Strength of Materials

${ }^{2}$ National Technical University of Ukraine "Kyiv Polytechnic Institute",

Department of Theoretical Mechanics
} 
it is not clearly defined criteria of applicability, in some cases the formulas for determining of the reduced stiffness are absent or don't have sufficient justification (for example, an oblique grid edges); there are no recommendations for the irregular arrangement of the ribs. That is why, only the methods that take into account the discrete setting are considered. Difficulties of analytical solutions are caused by the presence of explosive parameters in functions of shell stiffness. In this regard, the following areas were defined:

1. The searching for analytical solutions, for example, using the delta function in trigonometric series, which have a pulsed character and take into account jumps and breaks in the desired functions. It was noted that in contrast to the smooth shell the system of algebraic equations is obtained for the coefficients of series terms decomposition even with simple support it is compatible due to non-orthogonality of the trigonometric functions of discrete argument with arbitrary stiffness and ribs location.

2. In considering the ribbed shell as a contact problem it is used the dismemberment to a smooth shell and underpin ribsor smooth panels and edges are allocated and joined together. For example, in the shells with parallel ribs system and normal to the two hinged sides the solution is sought in the form of a single trigonometric series and then contact conditions along the lines of ribs for every smooth portion are performed. Here, as for all analytical solutions, the limitations in applicability of the method are determined by the function selection difficulties of certifying a different boundary conditions. The analytical methods of the solution for the cross-ribs system are more complicated.

An application of numerical analysis methods for the calculation of ribbed shells is available from a number of disadvantages of analytical solutions. A numerical solution method allows us to take into account different boundary and conjugation conditions, the presence of ribs, and etc.

Let us consider the basic relations. Using the Lagrange principle of possible displacements we have

$$
\delta \Pi=0 .
$$

It is possible to obtain the equation of stiffened shell equilibrium and static boundary conditions. In the case of thin membranes the deformation is presented as [1]

$$
\left.\begin{array}{c}
\varepsilon_{z}=\gamma_{x z}=\gamma_{y z}=0 \\
\varepsilon_{x}=\varepsilon_{x 0}+z \chi_{x} \\
\varepsilon_{y}=\varepsilon_{y 0}+z \chi_{y} \\
\gamma_{x y}=\gamma_{x y 0}+2 z \chi_{x y}
\end{array}\right\} \text {. }
$$

Components $\varepsilon_{x 0} \varepsilon_{y 0} \gamma_{x y 0}$ belong to the middle layer. In the case of sloping shells we have 
62

$$
\left.\begin{array}{rr}
\varepsilon_{x 0}=\frac{\partial U}{\partial x}+k_{x} w & \chi_{x}=-\frac{\partial^{2} w}{\partial x^{2}} \\
\varepsilon_{y 0}=\frac{\partial V}{\partial y}+k_{y} w & \chi_{y}=-\frac{\partial^{2} w}{\partial y^{2}} \\
\gamma_{x y 0}=\frac{\partial U}{\partial y}+\frac{\partial V}{\partial x}+2 k_{x y} w & \chi_{x y}=-\frac{\partial^{2} w}{\partial x \partial y}
\end{array}\right\},
$$

where $k_{x}, k_{y}, k_{x y}$ are the curvature of shell surface.

By substituting equation (2) (3) into (1) for a three-dimensional elastic body and by integrating a shell thickness in the range from $+\frac{1}{2} t$ to $-\frac{1}{2} t$ we vector variational equation for smooth thin elastic shells is obtained

$$
\iint_{W_{0}}\left(N_{x} \delta \varepsilon_{x 0}+N_{y} \delta \varepsilon_{y 0}+S_{x y 0} \delta \gamma_{x y 0}+M_{x} \delta \chi_{x}+M_{y} \delta+\right.
$$

$\left.+2 M_{x y} \delta \chi_{x y}\right) A B d \alpha d \beta=\iint_{W_{0}}(X \delta U+Y \delta V+Z \delta W) A B d \alpha d \beta$,

$X, Y, Z$ - are the intensity of the components of the total external load on the shell,

$W_{0}$ - is area of the middle surface of the shell. For sloping shell $A \approx B \approx 1$ and $d \alpha \approx d x, d \beta \approx d y$ (Fig. 1),

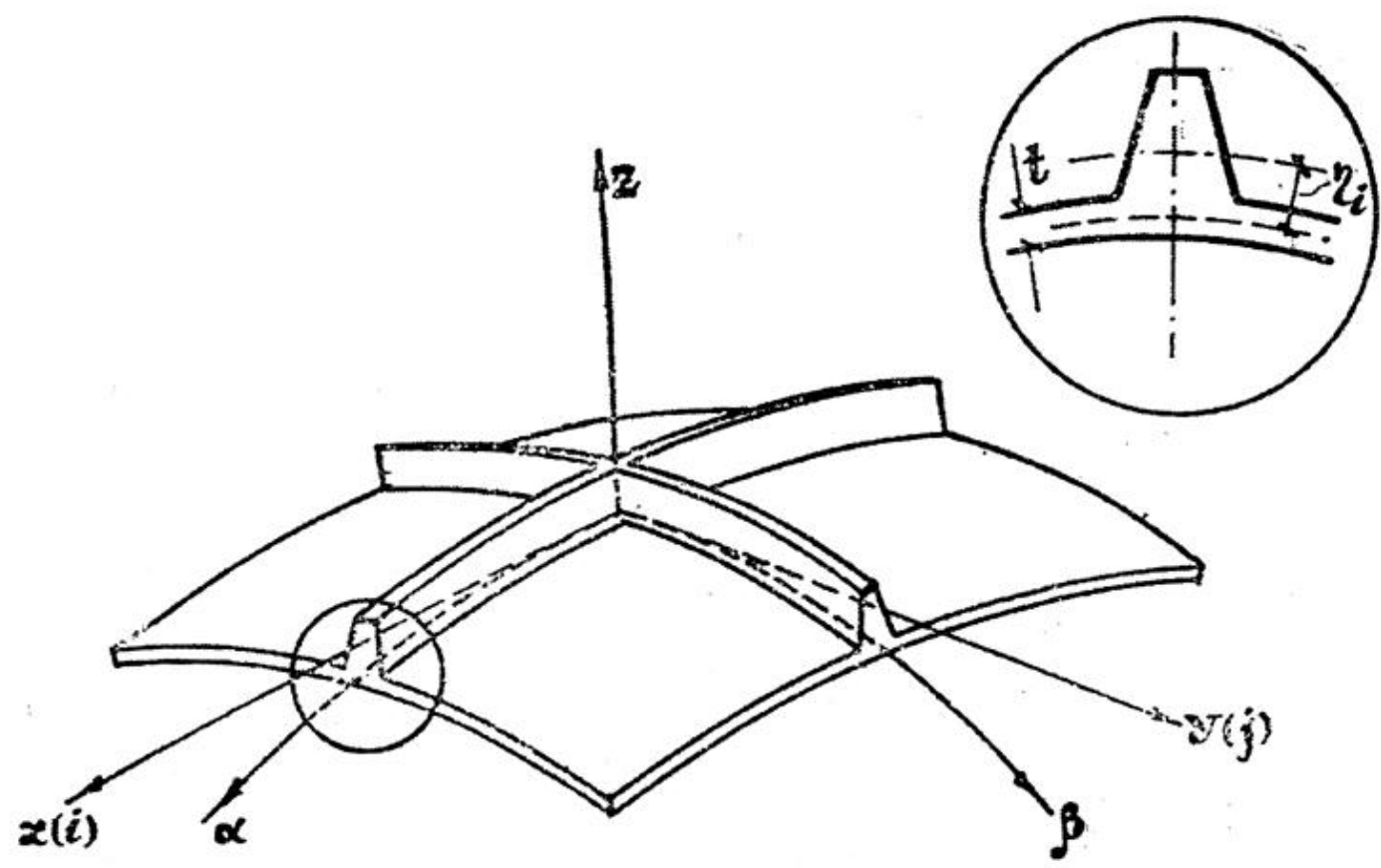

Figure. 1. The shell fragment with ribs

here is 


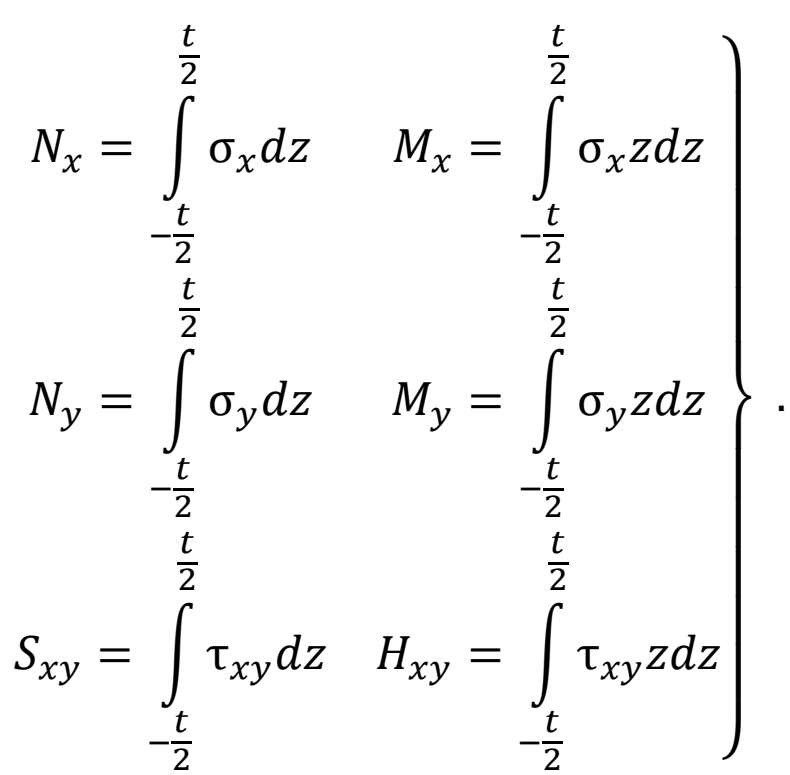

$A$ and $B$ are the coefficient of the first quadratic form of the middle surface of the shell in curvilinear orthogonal coordinates $\alpha$, $\beta$. The dependence, that is corresponding to the usual hypotheses of thin shells was adopted:

$$
\left.\begin{array}{l}
\tilde{A}=A\left(1+\frac{Z}{R_{x}}\right) \\
\tilde{B}=B\left(1+\frac{Z}{R_{y}}\right)
\end{array}\right\} .
$$

At the integrals of the form

$$
\int \sigma_{x}\left(1+\frac{Z}{R_{x}}\right)\left(1+\frac{Z}{R_{y}}\right) d z
$$

in expression (7) we used a simplification

$$
\left(1+\frac{Z}{R_{y}}\right) \approx\left(1+\frac{Z}{R_{x}}\right) \approx 1 .
$$

Accounting (Calculating) of these terms would lead to a more accurate expression for the effort (8) than the accuracy of the initial assumptions of the theory of shells. From equation (4) the variation equations for the curved beams can be obtained as a pure case. For example, for curvilinear beams with the axis $o_{i}$, which lies in a plane zoo, we obtain torsion and bending in two planes [1,2], taking into account the longitudinal deformation energy,

$$
\begin{aligned}
& \int\left(N_{i} \delta \varepsilon_{0 i}+M_{1 i} S \chi_{1 i}+M_{2 i} S \chi_{2 i}+H_{i} \delta S \chi_{i}\right) \tilde{A} d \alpha= \\
& =\int\left(X_{i} \delta U_{i}+Y_{i} \delta X_{i} \delta V_{i}+Z_{i} \delta W_{i}\right) A d \alpha,
\end{aligned}
$$


$X_{i}, Y_{i}, Z_{i}$ are the intensity components of total external load that are applied to the beam axis

$$
\begin{aligned}
& \varepsilon_{i 0}=\frac{\partial U_{i}}{\partial x}+k_{x} w_{i} \quad N_{i}=E F_{i} \varepsilon_{i 0} \\
& \chi_{1 i}=-\frac{\partial^{2} w_{i}}{\partial x^{2}} \quad M_{1 i}=E_{1 i} \chi_{1 i} \\
& \chi_{2 i}=-\frac{\partial^{2} v_{i}}{\partial x^{2}} \quad M_{2 i}=E I_{2 i} \chi_{2 i} \\
& \chi=-\frac{\partial \varphi_{\text {кр } i}}{\partial x} \quad H_{i}=G I_{\text {кр } i} \chi_{i}
\end{aligned}
$$

$\varphi_{\text {кр } i}$ is a twist angle.

Dependencies (6) are given for the case of a curvilinear beam with the axis $O X$.

Similar equations and dependencies will be for a curvilinear beam with the axis $O Y$, which lies in a plane $z o \beta$ [2]

$$
\begin{aligned}
& \int\left(N_{j} \delta \varepsilon_{j 0}+M_{1 j} S \chi_{1 j}+M_{2 j} S \chi_{2 j}+H_{j} \delta S \chi_{j}\right) \tilde{B} d \beta= \\
& =\int\left(X_{j} \delta U_{j}+Y_{j} \delta V_{j}+Z_{j} \delta W_{j}\right) B d \beta
\end{aligned}
$$

Where are

$$
\left.\begin{array}{cc}
\varepsilon_{j 0}=\frac{\partial V_{j}}{\partial y}+k_{y} w_{j} & N_{j}=E F_{j} \varepsilon_{j 0} \\
\chi_{1 j}=-\frac{\partial^{2} w_{j}}{\partial y^{2}} & M_{1 j}=E I_{1 j} \chi_{1 j} \\
\chi_{2 j}=-\frac{\partial^{2} U_{j}}{\partial y^{2}} & M_{2 j}=E I_{2 j} \chi_{2 j} \\
\chi_{j}=-\frac{\partial \varphi_{\text {кр } j}^{\partial y}}{H_{j}}=G I_{\text {кр } j} \chi_{j}
\end{array}\right\}
$$

If the beams are ribs for shell reinforcing (Figure 1), the conditions of deformation continuity between the ribs and the shell on the basis of the hypotheses of direct normal and incompressibility of fibers have the form:

$$
\left.\begin{array}{cc}
w_{i}=w & w_{j}=w \\
u_{i}=u-\zeta_{i} \frac{\partial w}{\partial x} & u_{j}=u-\zeta_{j} \frac{\partial w}{\partial x} \\
v_{i}=v-\zeta_{i} \frac{\partial w}{\partial y} & v_{j}=v-\zeta_{j} \frac{\partial w}{\partial y} \\
\varphi_{i}=\frac{\partial w}{\partial y} & \varphi_{j}=\frac{\partial w}{\partial x}
\end{array}\right\}
$$

The ribs are arranged eccentrically with respect to their median surface, $\eta$ - is the distance from the axis of the beam to the middle surface of the shell. 
For ribs on the inner surface of the shell the magnitude $\zeta$ is taken with the sign «-».

\section{Methods of solutions}

The variational equation for thin elastic shell, that supported by ribs $i$-th and $j$-th directions will look like

$$
\delta V+\sum_{i=1,2}^{n} \delta V_{i}+\sum_{j=1,2}^{m} \delta V_{j}-\delta T-\sum_{i=1,2}^{n} \delta T_{i}+\sum_{j=1,2}^{m} \delta T_{j}=0
$$

Where $V, V_{i}, V_{j}$ are the potential energy of deformation of smooth shell and ribs, $T, T_{i}, T_{j}$ are the potential of the external forces that are applied to the smooth shell and ribs, $m$ and $n$ the number of ribs respectively of $i$-th and $j$-th directions. $m$ and $n$ are the numbers

This sum includes summands of so many equations as there are ribs of corresponding directions. The analytical solution of ribbed shells state is obtained in simple cases of supporting, i. e. with boundary conditions of Navier type. In this case, the displacement functions are represented as a Fourier series $[3,4]$. To solve practical problems with more complicated conditions of fixing it is necessary to apply numerical methods. Currently, the most popular is the finite element method [5-7]. The main stages of the decisions are: the splitting of the shell structure on the elements; drawing up the resolving equations by the method of the beginning of possible movements; definition of nodal displacements, strains and stresses. However, despite the effectiveness of finite element method in the calculation of shells, there are a number of difficulties associated with the formation, storage and operating with the global stiffness matrix. To avoid these difficulties in this work a campaign based on the variationalgrid method of formation the full functionality of the potential energy of the system and minimizing it by coordinate wise descent method is applied [8]. In constructing the variational-grid schemes a functional of the system (10) for the final measure space of admissible functions $\Omega_{h}$ has the form:

$$
\ni\left(v_{h}\right)=\frac{1}{2} a\left(v_{h}, v_{h}\right)-f\left(v_{h}\right) ; \quad v_{h} \in \Omega_{h}
$$

and variational problem is replaced by approximate

$$
u_{h} \in \Omega_{h} ; \ni\left(u_{h}\right)=\inf _{v_{h} \in \Omega_{h}} Э\left(v_{h}\right)
$$

which is also has the unique solution. There is a convergence of approximation solution $u_{h} \in \Omega_{h}$ to an exact $u \in \Omega$, if an equation is performed:

$$
\lim _{h \rightarrow 0}\left\|u-u_{h}\right\|_{V}=0
$$


The solution is searched as follows by coordinate-wise descent method. Let $\vec{v}^{k}=\left(v_{1}^{k}, \ldots, v_{N}^{k}\right)$ is a vector of nodal displacements in current approximation, then the next approaching being built as:

$$
\overrightarrow{\mathrm{v}}^{k+1}=\overrightarrow{\mathrm{v}}^{k}+\lambda_{i}^{k+i} \vec{e}_{i}, \quad i=1, \ldots, N
$$

The magnitude $\lambda_{i}^{k+1}$ is determined from the conditions of maximum of functional decreasing

$$
\frac{\partial \Delta \ni}{\partial \lambda_{i}^{k+1}}=0
$$

In practice relaxation an iterative process continues until the ratio $\left\|\vec{\lambda}^{k}\right\| /\left\|\overrightarrow{\mathrm{v}}^{k}\right\|$ becomes less than a certain, predetermined number $\epsilon>0$. The choice of last ) is performed so that the iterative process error was approximately equal to the error of displacement approximation $0\left(h^{s}\right)$. Thus, the criterion adopted as 'Stop' is written as follows:

In practice relaxation an iterative process continues until the ratio $\left\|\vec{\lambda}^{k}\right\| /\left\|\overrightarrow{\mathrm{v}}^{k}\right\|$ becomes less than a certain, predetermined number $\epsilon>0$. The choice of this number is performed so that the iterative process error was approximately equal to the error of displacement approximation $0\left(h^{s}\right)$. Thus, the criterion adopted as 'Stop' is written as follows:

$$
\frac{\left\|\vec{\lambda}^{k}\right\|}{\left\|\overrightarrow{\mathrm{v}}^{k}\right\|}<\epsilon
$$

where $\left\|\vec{\lambda}^{k}\right\|,\left\|\overrightarrow{\mathrm{v}}^{k}\right\|$ are the norms of vectors increments and displacement on $k$-th iteration. For approximation of displacements the linear polynomials for tangential displacements and incomplete cubic polynomial for deflection were used in work. To investigate the effectiveness of this approach the comparative data in solving the problem of bending the shell by finite element method (MFE) and by method of coordinate wise descent (MCWD)(Table 1) were obtained.

\begin{tabular}{|c|c|c|c|c|c|}
\hline \multirow{2}{*}{$\mathbf{L}(\mathbf{m})$} & \multirow{2}{*}{$\mathbf{R}(\mathbf{m})$} & \multirow{2}{*}{$\begin{array}{c}\text { Number of } \\
\text { elements }\end{array}$} & \multicolumn{2}{|c|}{$\mathrm{W}_{\max } * 10^{5}(\mathrm{~m})$} & \multirow{2}{*}{$\Delta_{1} \%$} \\
\hline & & & MCWD & MFE & \\
\hline \multirow{4}{*}{0,85} & \multirow{4}{*}{0,8} & $100 \times 100$ & 9,558 & 10,22 & 6,5 \\
\hline & & $150 \times 150$ & 9,326 & 9,86 & 5,4 \\
\hline & & $200 \times 200$ & 9,228 & 9,74 & 4,9 \\
\hline & & $250 \times 250$ & 9,186 & 9,62 & 4,5 \\
\hline
\end{tabular}

Table 1.

The values of the maximum deflection of sloping shell with different grids 


\begin{tabular}{|c|c|c|c|c|c|}
\hline \hline \multirow{2}{*}{$\mathbf{L}(\mathbf{m})$} & \multirow{2}{*}{$\mathbf{R}(\mathbf{m})$} & \multirow{2}{*}{$\begin{array}{c}\text { Number of } \\
\text { elements }\end{array}$} & \multicolumn{2}{|c|}{$\mathbf{W}_{\mathbf{m a x}}{ }^{*} \mathbf{1 0}$ (m) } & \multirow{2}{*}{$\boldsymbol{\Delta}_{\mathbf{1}} \%$} \\
\cline { 4 - 5 } & & $\mathbf{M C W D}$ & $\mathbf{M F E}$ & \\
\hline \multirow{2}{*}{0,65} & \multirow{2}{*}{0,6} & $100 \times 100$ & 7,446 & 7,9 & 5,7 \\
& & $200 \times 200$ & 7,142 & 7,5 & 4,8 \\
\hline
\end{tabular}

\section{Conclusions}

In this paper we propose an approach for the calculation of the stressstrain state of supported shells which is based on the variational-grid method of constructing a finite-functional of potential energy and the next minimization of it by iterative method of coordinate descent. The application of this approach makes it possible to avoid the difficulties deals with the formation, storage and operating with a global matrix of the rigidity and allows to solve the problem of large dimension using only PC memory.

\section{References}

1. Абовский Н. П. Ребристые оболочки: В 2-х т. - Красноярск: Изд-во Крас-нояр. политехн., ин-та, 1967.

2. Абовский Н. П. Вариационные принципы теории упругости и теории оболочек. / Н. П. Абовский, Н. П. Андреев, А. П. Дерюга- М.: Наука, 1978. $228 \mathrm{c}$.

3. Амбариумян С. А. Теория анизотропных пластин: Прочность, устойчивость и колебания. 2-е изд., перераб. и доп. - М.: Наука. Гл. ред. физ.мат. лит., 1987.-360 с.

4. Амиро И. Я. Теория ребристых оболочек / И. Я. Амиро, В. А. Заруцкий // Методы расчета оболочек: В 5-ти т. Т.2. Киев: Наук, думка, 1980. $368 \mathrm{c}$.

5. Галлагер Р. Метод конечных элементов. Основы: Пер. с англ. - М.: Мир, 1984-428 С.

6. Зенкевич О. Метод конечных элементов в технике - М.: Мир, 1975.$542 \mathrm{C}$.

7. Сегерлинд Л. Применение метода конечных элементов - М.: Мир, 1979. - 392 C.

8. Бабенко A. E. Применение и развитие метода покоординатного спуска в задачах определения напряженно-деформированного состояния при статических и вибрационных нагрузках /А. Е. Бабенко, Н. И. Бобырь, С. Л. Бойко, О. А. Боронко - К.: Инрес, 2005. - 264c. 